\title{
A EXTRAFISCALIDADE DO IMPOSTO SOBRE A IMPORTAÇÃO EM FAVOR DA AQUISIÇÃO DE OBRAS DE ARTE
}

\section{THE NON-FISCAL ATTRIBUTE OF THE IMPORT DUTY IN FAVOR OF THE ACQUISITION OF ARTWORK}

\author{
Elizabete Rosa de Mello \\ Universidade Federal de Juiz de Fora - UFJF - (Juiz de Fora, MG, Brasil) \\ Maria Laura Clemente Morais \\ Universidade Federal de Juiz de Fora - UFJF - (Juiz de Fora, MG, Brasil)
}

Recebimento: 26 ago. 2018

Aceitação: 24 set. 2018

\begin{abstract}
Como citar este artigo / How to cite this article (informe a data atual de acesso / inform the current date of access):
MELLO, Elizabete Rosa de; MORAIS, Maria Laura Clemente. A extrafiscalidade do imposto sobre a importação em favor da aquisição de obras de arte. Revista da Faculdade de Direito UFPR, Curitiba, PR, Brasil, v. 63, n. 3, p. 213231, set./dez. 2018. ISSN 2236-7284. Disponível em: <https://revistas.ufpr.br/direito/article/view/61198>. Acesso em: 22 dez. 2018. DOI: http://dx.doi.org/10.5380/rfdufpr.v63i3.61198.
\end{abstract}

\section{RESUMO}

Este trabalho objetiva expor as razões para a concessão de isenção total do imposto sobre a importação de obras de arte adquiridas por particulares. O mencionado tributo possui caráter eminentemente extrafiscal, sendo sua função precípua a promoção do equilíbrio entre os mercados interno e externo. A partir da definição de arte como mercadoria sui generis, evidencia-se a inexistência de similaridade entre objetos artísticos, pelo que se demonstra a impropriedade da cobrança do referido imposto aduaneiro sobre a entrada definitiva de obras de arte, as quais não competem com qualquer outro produto nacional. Ademais, o valor cultural dessa espécie de mercadoria exigiria o fomento ao seu ingresso no Brasil, ainda que ele se dê pela aquisição privada, com o intuito de enriquecer o patrimônio artístico nacional e promover o aquecimento do mercado nacional de arte. A metodologia adotada é crítico-dialética, com abordagens quantitativa e qualitativa, por meio da análise das legislações pátria e alienígena e do exame de dados e conceitos extraídos de material bibliográfico.

\section{PALAVRAS-CHAVE}

Imposto sobre a importação. Extrafiscalidade. Obras de arte.

\begin{abstract}
This paper aims to expose the reasons why private acquisition of artworks should be considered dutyfree in relation to the import duty, which is a non-fiscal tax. In fact, its main goal is to promote the balance between inner and external markets. Given the definition of art as a sui generis merchandise, it is pointed that no artwork can be similar to another; therefore, the charge of import duty is improper in this case, once foreign art objects do not compete with any other national product. Moreover, its cultural value would require the promotion of its entrance in the country, even though it is due to a private purchase, considering that it is able to stimulate enrichment of the national artistic patrimony and foments a higher development of the Brazilian artwork market. It was employed a criticaldialectical methodology, with the using of both quantitative and qualitative approaches, by the
\end{abstract}


analysis of national and foreign legislations and the assessment of data and concepts extracted from bibliographic materials.

\section{KEYWORDS}

Import duty. Non-fiscal tax. Artwork.

\section{INTRODUÇÃO}

A função precípua do imposto sobre a importação de produtos estrangeiros é o controle da entrada de mercadorias alóctones no País, com o propósito de proteger os produtos de origem nacional. O objetivo arrecadatório em tal contexto possui, desse modo, importância secundária. A fixação das alíquotas e a concessão de benefícios fiscais em relação a este tributo se orientam por meio da eventual existência de competitividade entre um produto nacional e um produto de origem estrangeira, quando similares e, portanto, aptos a substituir um ao outro. Ao contrário, a incapacidade do mercado brasileiro de suprir a demanda por determinado produto cria a necessidade de fomento à sua importação.

Sob a ótica da extrafiscalidade do imposto sobre a importação, o presente estudo propõe uma crítica à cobrança do referido tributo sobre o ingresso definitivo de objetos artísticos no território nacional, decorrente de sua aquisição particular. Isso porque a obra de arte é uma mercadoria peculiar e seu mercado não comporta a possibilidade de substituição de um produto por outro com características similares. A não aplicabilidade da noção de similaridade ao caso une-se à relevância cultural do produto artístico, razão pela qual é imperioso o estímulo à importação dessa espécie de mercadoria, visando ao enriquecimento do patrimônio artístico pátrio e ao aquecimento do mercado de arte nacional.

O artigo se estrutura da seguinte forma: inicialmente, no item 1, são expostos os óbices enfrentados para a importação de obras de arte no Brasil ocasionados pela atividade fiscal, com ênfase na excessiva carga tributária incidente sobre a operação. O item 2 trata dos conceitos doutrinários de fiscalidade e extrafiscalidade, com o intuito de se evidenciar a possibilidade de utilização dos tributos como instrumento para a persecução de fins diversos da arrecadação de receita para o Estado, sem que esta finalidade desapareça, assumindo posição secundária em determinadas circunstâncias. As especificidades do imposto sobre a importação são abordadas no item 3, em que se destaca o caráter tradicionalmente extrafiscal desse tributo. No item subsequente, a obra de arte é definida como mercadoria sui generis, em razão de sua singularidade, por meio do que se afasta a noção de similaridade. Por fim, no item 5, demonstra-se a pertinência da concessão de isenção total do imposto sobre a importação às obras de arte, por meio da análise da legislação ora vigente e da estimativa de 
redução significativa do valor integral dos tributos devidos em razão do ingresso de um objeto artístico no território nacional. Nessa oportunidade, também são expostos exemplos de legislações alienígenas.

O tema se desenvolve a partir da metodologia crítico-dialética, procurando-se evidenciar a inadequação da legislação em vigor em face das necessidades atuais do mercado de arte no Brasil. Há a utilização do método qualitativo, para a delimitação de noções e conceitos caros ao debate, como extrafiscalidade e arte como mercadoria sui generis. O método quantitativo também é empregado, ao se averiguar a carga tributária incidente sobre a importação de objetos artísticos, bem como na aferição de dados sobre o mercado internacional de arte. Este estudo se ampara especialmente em pesquisa bibliográfica e na análise das legislações pátria e alienígena.

\section{ATIVIDADE FISCAL E ÓBICES À IMPORTAÇÃO DE OBRAS DE ARTE}

É necessário, inicialmente, descrever o atual cenário da atividade tributária sobre a importação de objetos de arte no Brasil, com o intuito de se evidenciar a excessiva carga tributária incidente sobre o ingresso de objetos artísticos no País, o que, aliado à função extrafiscal do imposto sobre a importação (ponto a ser tratado nos itens subsequentes), demonstrará a pertinência da concessão de isenção total a essa mercadoria quanto ao referido tributo.

A elevada tributação no Brasil há muito tem sido alvo de desaprovação popular, haja vista a conhecida má gestão dos recursos advindos da atividade fiscal. As críticas à tributação excessiva direcionam-se comumente aos tributos indiretos incidentes sobre o consumo, por recaírem sobre a parcela da população com menor capacidade contributiva, havendo notória injustiça na atuação fiscal. Na importação, de modo diverso, a alta carga tributária possui uma justificativa, apoiando-se na lógica de proteção do produto nacional em face de mercadorias estrangeiras similares.

O imposto sobre a importação de produtos estrangeiros, especificamente, prestar-se-ia a criar ou a preservar artificialmente a atratividade dos produtos de origem brasileira no próprio mercado nacional, o que seria necessário tão somente quando verificada uma efetiva competição entre a mercadoria produzida no Brasil e produtos importados. Esse cenário se configura quando é possível empregar a noção de similaridade, ou seja, na hipótese em que é concebível a substituição da mercadoria estrangeira pela nacional e vice-versa.

No caso da importação de obras de arte, não se observa tal possibilidade, uma vez que a arte como mercadoria possui natureza sui generis, em virtude de sua importância não se concentrar em sua eventual utilidade, mas sim na experiência subjetiva que é capaz de proporcionar. Essa qualidade 
do objeto artístico será mais bem tratada mais adiante. Importa, por ora, pontuar a impertinência da discussão em torno da similaridade quando a mercadoria em questão é a arte. Tal constatação, aliada à relevância cultural ${ }^{1}$ do produto artístico, conduzirá à conclusão de que a mercadoria ora em estudo é merecedora de isenção do imposto sobre a importação. A concessão desse benefício seria o primeiro passo para a desoneração do mercado de arte brasileiro, e, por conseguinte, para a promoção de sua internacionalização e do enriquecimento cultural do País.

Um relatório elaborado por The European Fine Art Foundation (TEFAF), com organização de Clare McAndrew (2013), sobre o mercado de arte global, com foco na China e no Brasil, apontou como principal óbice ao desenvolvimento do mercado artístico brasileiro a legislação tributária, com ênfase na forma como a importação é regulada:

A major stumbling block in the international development of the Brazilian market has been its tax laws and particularly its import regulations, which have made it very difficult for Brazilian galleries to sell international art, and for public collections in Brazil to import art or to build international collections (MCANDREW, 2013, p. 173)².

As dificuldades enfrentadas na importação, referidas no estudo, abrangem a complexa legislação fiscal e a elevada carga tributária incidentes sobre a operação. Há um significativo número de tributos devidos por ocasião do ingresso de bem estrangeiro no território nacional, o que não apenas onera excessivamente o sujeito passivo, mas também torna caótico o cumprimento das diversas obrigações tributárias (principais e acessórias) que surgem com a importação. Esse quadro é ratificado na pesquisa promovida em 2015 pela Associação Brasileira de Arte Contemporânea (ABACT) e pela Agência Brasileira de Promoção de Exportações e Investimentos (Apex-Brasil), por meio do programa Latitude - Platform for Brazilian Art Galleries Abroad. Seus resultados indicam que a carga tributária representa uma das principais barreiras ao desenvolvimento das galerias nacionais, tendo sido superada tão somente pela instabilidade econômica do País. Sobrepõe-se a fatores como dificuldades de gestão e de planejamento e rede de contatos limitada (FIALHO, 2015).

Incidem sobre a entrada definitiva de uma obra de arte no território nacional o imposto sobre a importação de produtos estrangeiros (II), o PIS-importação, a COFINS-importação e o imposto sobre produtos industrializados vinculado à importação (IPI-vinculado), além do imposto sobre

\footnotetext{
${ }^{1}$ No presente artigo, o uso da palavra “cultura” se aproxima da definição fornecida por seu uso coloquial. Segundo o antropólogo Ralph Linton, "Como termo geral, cultura significa a herança social total da humanidade; como termo específico, uma cultura significa uma determinada variante da herança social” (LINTON, 1968, p. 90). Emprega-se, nesta oportunidade, a primeira definição.

2 "Uma grande pedra no caminho do desenvolvimento internacional do mercado brasileiro tem sido sua legislação tributária e, particularmente, a regulamentação sobre a importação, o que tem tornado muito difícil a venda de arte internacional pelas galerias brasileiras, e a importação e montagem de coleções internacionais pelas coleções públicas no Brasil” (tradução nossa).
} 
operações relativas à circulação de mercadorias e prestação de serviços de transporte interestadual e intermunicipal e de comunicação vinculado à importação (ICMS-vinculado) (MACEDO, 2015).

Como exemplo, considere-se a importação de um quadro, com valor estimado em R\$ 20.000,00 (vinte mil reais) e valor aduaneiro (acrescido do frete internacional) de R $\mathbf{2 3 . 0 0 0 , 0 0 ~ ( v i n t e ~}$ e três mil reais), com destino ao Estado de São Paulo e proveniente de país com o qual o Brasil não possua acordo com impacto na atividade fiscal aduaneira. Sobre essa operação, incidiria a seguinte carga tributária, segundo dados da Receita Federal do Brasil e da Secretaria da Fazenda do Estado de São Paulo:

Tabela 1 - Valor da carga tributária incidente sobre a importação de um quadro com valor aduaneiro equivalente a R\$23.000,00 em maio de 2018

\begin{tabular}{ccc}
\hline Tributo & Alíquota (\%) & Valor $\mathbf{( R \mathbf { ~ } )}$ \\
\hline II & 4 & 920,00 \\
IPI & 0 & 0,00 \\
PIS & 2,10 & 483,00 \\
COFINS & 9,65 & $2.219,50$ \\
Taxa de utilização do SISCOMEX & & $40,00^{3}$ \\
ICMS vinculado à importação & 18 & $5.852,74$ \\
$\Sigma$ & & $\mathbf{9 . 5 1 5 , 2 4}$ \\
\hline
\end{tabular}

Fonte: dados obtidos da Receita Federal do Brasil (2018) e da Secretaria da Fazenda do Estado de São Paulo (2018).

Verifica-se, portanto, que a carga tributária pode ultrapassar $41 \%$ do valor aduaneiro do objeto de arte, chegando a 47,5\% de seu importe original. O alto valor que a soma dos tributos incidentes sobre a importação pode alcançar certamente caracteriza um desestímulo à incorporação de obras de arte, provenientes do exterior, ao patrimônio brasileiro, sendo questionável, inclusive, a observância ao princípio constitucional da vedação ao efeito confiscatório (artigo 150, inciso IV, CRFB/1988).

Há, na legislação pátria, poucos incentivos fiscais ao setor artístico quanto à importação. Mencione-se o Convênio ICMS nº 01/2013, por meio do qual os estados de Minas Gerais, do Rio de Janeiro e de São Paulo estão autorizados a conceder isenção na importação e nas saídas de obras de

\footnotetext{
${ }^{3} \mathrm{O}$ valor utilizado no cálculo da taxa SISCOMEX está em conformidade com o estabelecido pelo artigo $3^{\circ}$ da Lei $n^{\circ}$ 9.716/1998. Não foi aplicado o disposto na Portaria do Ministério da Fazenda n $257 / 2011$ em observância à decisão quanto à sua ilegalidade proferida pelo Supremo Tribunal Federal no Agravo Regimental no Recurso Extraordinário $\mathrm{n}^{\circ}$ 1.095.001/SC, em seis de março de 2018.
} 
arte destinadas à comercialização na Feira Internacional de Arte do Rio de Janeiro (ArtRio) e na Feira Internacional de Arte de São Paulo (SP Arte).

Quanto ao imposto sobre a importação, especificamente, existe o regime de admissão temporária, regulamentado pela Instrução Normativa da Receita Federal do Brasil no 1.600/2015, por meio do qual se promove a suspensão total da exigibilidade de tributos incidentes sobre a importação de bem destinado a fim não econômico, ou parcial, no caso de produto que ingressa em território nacional com propósito econômico, caso a mercadoria permaneça no País por determinado lapso temporal, regressando, ao final do prazo, ao país de origem. Ademais, a doação, a museus, de quadros, pinturas, desenhos e originais de gravuras, estampas e litografias, além de produções originais de arte estatuária ou de escultura e de antiguidades (peças com mais de cem anos) já goza de isenção do referido imposto aduaneiro (Lei $\left.n^{\circ} 8.961 / 1994\right)$.

Entende-se, contudo, haver a necessidade de extensão da isenção do imposto sobre a importação ao ingresso definitivo de obras de valor artístico no País decorrente da aquisição por particulares. Isso porque, conforme será exposto, os tributos aduaneiros possuem tradicional finalidade extrafiscal, perseguindo, sobretudo, a proteção dos produtos nacionais em face de mercadorias estrangeiras similares. Demonstrar-se-á que, a depender da natureza do produto, surge, ao contrário, a necessidade de fomento à sua entrada em território nacional. Portanto, é imprescindível para este estudo a análise da possibilidade de os tributos assumirem função diversa da mera arrecadação de receita para o Estado.

\section{FINALIDADES DOS TRIBUTOS: FISCAL E EXTRAFISCAL}

A fim de se demonstrar a função precípua do imposto sobre a importação, deve-se, inicialmente, proceder à definição dos conceitos de fiscalidade e extrafiscalidade, os quais se relacionam à finalidade da atividade tributária.

Sob a perspectiva da função fiscal, a instituição de tributos não possui interesse diverso do abastecimento dos cofres públicos (CARVALHO, 2009). A atividade tributária manifesta-se, nesse contexto, como mero instrumento arrecadatório, visando apenas à produção de receita derivada, ou seja, ao recolhimento de recursos financeiros advindos do patrimônio dos particulares, enquadrados como contribuintes ou responsáveis tributários. Contudo, não raramente, os tributos assumem também um caráter extrafiscal, ou seja, direcionam-se ao alcance de objetivos de natureza diversa da arrecadação, não obstante esta seja sempre um de seus fins (principal ou secundário). 
A extrafiscalidade, em sentido amplo, é uma característica das normas com finalidade que não se relaciona com a obtenção de recursos para o Estado. Assim interpretado, o termo pode ser empregado inclusive como referência a dispositivos normativos que não se inserem no regime tributário (SCHOUERI, 2005). Em stricto sensu, verifica-se a função extrafiscal quando há o “[...] emprego deliberado do instrumento tributário para finalidades não financeiras, mas regulatórias de comportamentos sociais, em matéria econômica, social e política” (ATALIBA, 1968, p. 151). Consiste, portanto, em um modo de ingerência do Estado em determinados hábitos e condutas do contribuinte, por meio da sugestão à escolha de dada opção favorável ao interesse público. A intervenção estatal no comportamento dos particulares ocorre, na extrafiscalidade em sentido estrito, por indução, ou seja, a partir de medidas de incentivo ou desestímulo a determinada conduta, verificando-se a persistência de uma margem de escolha para o particular (SCHOUERI, 2005) ${ }^{4}$.

A função extrafiscal conquistou maior relevância com a passagem do modelo liberal clássico para o Estado de Bem-Estar Social, em que o Estado avoca a responsabilidade de proteção e garantia não apenas dos direitos de liberdade, mas também dos direitos classificados como de segunda geração ou dimensão, de ordem social. Ao lado do objetivo precípuo de constituição de receita para a máquina estatal, a atividade tributária torna-se instrumento de incentivo ou, ainda, de desestímulo a determinadas práticas econômicas, conforme o interesse público (TORRES, 2011).

No direito brasileiro, observa-se uma expansão gradual da utilização dos tributos para fins diversos da arrecadação. No Império e na República Velha, as tarifas alfandegárias eram o único exemplo de extrafiscalidade. Em 1941, foi editado o Decreto-Lei $n^{\circ} 3.200$, que estabelecia alíquotas diferenciadas para o imposto de renda conforme a configuração do núcleo familiar do contribuinte, com objetivo extrafiscal ligado à formação demográfica do País. Destaque-se, ainda, a Lei $\mathrm{n}^{\circ}$ 3.692/1959, que introduziu na legislação pátria um sistema de incentivos fiscais destinados ao fomento do desenvolvimento da Região Nordeste. A segunda metade do século XX testemunhou, ainda, a ampliação do uso extrafiscal dos tributos incidentes sobre o comércio exterior (SCHOUREI, 2005). A CRFB/1988 contemplou uma variedade de disposições pertinentes à ordem tributária com caráter extrafiscal, como as imunidades previstas em seu artigo 150, inciso VI, a progressividade dos impostos sobre a renda e sobre a propriedade territorial rural (artigo 153, $\S 2^{\circ}$, inciso I, e $\S 4^{\circ}$, inciso I), a seletividade do imposto sobre produtos industrializados (artigo 153, § $3^{\circ}$, inciso I), a

\footnotetext{
${ }^{4}$ Em razão da possibilidade de interpretação e aplicação amplas do vocábulo “extrafiscalidade”, Luís Eduardo Schoueri (2005) opta pelo emprego, em seu lugar, da expressão “normas tributárias indutoras”, apta a restringir seu estudo às normas de tributação conexas ao domínio econômico.
} 
possibilidade de instituição de contribuições de intervenção no domínio econômico (artigo 149), entre outras.

A extrafiscalidade, em alguns casos, se apresenta como uma característica de importância secundária em relação ao objetivo arrecadatório, como ocorre com o imposto de renda, cuja progressividade opera também como mecanismo de redistribuição de renda (ALEXANDRE, 2017). Em circunstâncias como esta, a função extrafiscal, embora de considerável relevância, não compõe o fim último da atividade tributária, que permanece alocado na necessidade de acúmulo de receita para o Estado. Conclui-se, portanto, que qualquer tributo é suscetível de ser utilizado para fins diversos da arrecadação de recursos financeiros, ainda que esta persista como sua finalidade precípua, podendo a extrafiscalidade se manifestar de diferentes formas, como por intermédio de isenções (gratuitas ou onerosas), anistia, remissão e estabelecimento de alíquotas mais elevadas ou reduzidas.

Certos tributos, por sua vez, possuem viés extrafiscal de modo mais intenso, sobressaindose ao propósito fiscal, o que se verifica, por exemplo, no imposto sobre operações de crédito, câmbio e seguro ou relativas a títulos ou valores mobiliários (IOF) e nos impostos aduaneiros (sobre a importação e a exportação). Luciano Amaro (2016), não por acaso, utiliza o termo "tributos regulatórios” ao se referir àqueles incidentes sobre o comércio exterior, exatamente em razão de a atividade tributária, nessas situações, operar como meio de atuação estatal no mercado. A arrecadação de recursos financeiros, em tal hipótese, é apenas uma consequência reflexa da tributação, a qual então visa primordialmente a influir em determinado comportamento do contribuinte.

Observar-se-ão, adiante, as especificidades do imposto sobre a importação, o qual se volta tradicionalmente a objetivos extrafiscais, tendo como escopo o equilíbrio entre os mercados nacional e internacional e, em regra, a proteção dos produtos de origem brasileira, subsistindo a arrecadação como fim secundário, em virtude da presença compulsória do elemento fiscal.

\section{IMPOSTO SOBRE A IMPORTAÇÃO DE PRODUTOS ESTRANGEIROS}

O imposto sobre a importação de produtos estrangeiros, previsto no artigo 153, inciso I, da Constituição da República Federativa do Brasil de 1988, é de competência da União, e é regulamentado principalmente pelo Código Tributário Nacional (CTN), entre os artigos 19 e 22, e pelo Decreto-Lei no 37/1966.

O fato gerador desse imposto ocorre com a entrada da mercadoria no território nacional (artigo 19 do CTN, combinado com o artigo $1^{\circ}$ do Decreto-Lei $n^{\circ} 37 / 1966$ ), ressalvando-se os produtos destinados ao consumo, cujo fato gerador é identificado com o momento do despacho 
aduaneiro, realizado mediante o registro da declaração de importação no Sistema Integrado de Comércio Exterior (SISCOMEX), nos termos dos artigos 23 e 44 do Decreto-Lei nº 37/1966. A base de cálculo, denominada valor aduaneiro, é aferida conforme os parâmetros estabelecidos pelo Acordo sobre a Implementação do Artigo VII do GATT (AVA-GATT), aprovado pelo Decreto Legislativo $n^{\circ} 30 / 1994$ e promulgado pelo Decreto Executivo $n^{\circ}$ 1.355/1994.

A alíquota varia de acordo com o produto a ser importado. Ressalte-se que, desde 1995, o Brasil adota a Tarifa Externa Comum (TEC), que padronizou as alíquotas incidentes sobre os produtos estrangeiros que adentram o bloco econômico sul-americano. A TEC tem como base de classificação das mercadorias a Nomenclatura Comum do MERCOSUL (NCM), a qual segue o método internacional de discriminação de mercadorias, denominado Sistema Harmonizado de Designação e Codificação de Mercadorias, ou simplesmente Sistema Harmonizado (SH). Os esclarecimentos quanto às mercadorias que de fato se enquadram nos diversos capítulos que compõem o SH estão expostos nas Notas Explicativas do Sistema Harmonizado de Designação e de Codificação de Mercadorias (NESH).

Em virtude da volatilidade da economia (nacional e internacional), aos tributos que possuem finalidade extrafiscal ligada à intervenção no mercado, como o imposto sobre a importação, não são impostas as limitações constitucionais ao poder de tributar referentes aos princípios da anterioridade de exercício e da anterioridade nonagesimal, nos termos do artigo 150, $\S 1^{\circ}$, da Carta Magna pátria, bem como ao princípio da legalidade estrita, segundo o artigo 153, § $1^{\circ}$, da CRFB/1988.

O fim precípuo do imposto sobre a importação tem natureza extrafiscal. Traduz-se na persecução do equilíbrio entre os mercados interno e externo, com o intuito de proteger a produção nacional, tornando-a mais atraente para o consumo em face de mercadorias similares de origem estrangeira. A arrecadação é uma consequência da cobrança do imposto, sendo de fato um objetivo apenas ocasionalmente (BARROS, 1991). Viveiros de Castro, em 1901, já mencionava a extrafiscalidade do imposto ora em estudo, defendendo, à época, que as "tarifas alfandegárias" se tornassem exclusivamente fiscais (CASTRO, 1901).

Desse modo, há a incidência do imposto sobre a importação com alíquotas maiores sobre produtos ingressados no mercado brasileiro quando da existência de artigo nacional com finalidade e qualidade semelhantes às daquele. Um exemplo é a alíquota do imposto incidente sobre a importação de peças de vestuário e acessórios compreendidos entre os Capítulos 61 e 62 da NCM, fixada em $35 \%$.

Existem, ao contrário, produtos estrangeiros que gozam de benefícios fiscais, em razão da escassez ou ausência de mercadoria similar produzida no Brasil, havendo, portanto, a necessidade de 
estímulo à sua incorporação ao comércio do País, com o fim de suprir a carência. É o que se verifica no imposto cobrado pela importação de alguns aparelhos médico-cirúrgicos dispostos no Capítulo 90 da NCM, cuja alíquota é de zero por cento.

O viés extrafiscal historicamente preeminente do imposto sobre a importação denuncia a impropriedade de sua cobrança sobre objetos de arte, dada sua natureza peculiar como mercadoria, conforme explanação a ser realizada no próximo item.

\section{ARTE COMO MERCADORIA SUI GENERIS}

O conceito de arte é tema demasiado controvertido em seu campo específico de estudo, em virtude da ampliação das formas de expressão artística a partir da Arte Moderna e, sobretudo, na Arte Contemporânea. Uma discussão profunda a respeito dos limites da arte extrapola o objetivo do presente estudo, o qual, no que concerne ao objeto artístico, restringe-se a discorrer sobre a relação entre arte e mercadoria.

Consideram-se objetos de arte, para a finalidade deste artigo, os bens assim compreendidos juridicamente. Isso porque a constituição da arte como mercadoria, na sociedade capitalista, realizase por meio da definição que a arte recebe do direito (MASCARO, 2015). Para fins de tributação, de modo específico, enquadram-se como obras de arte as mercadorias dispostas no Capítulo 97 da NCM, entre as posições 97.01 e 97.03, quais sejam, de acordo a descrição das Notas Explicativas do Sistema Harmonizado de Designação e de Codificação de Mercadorias (NESH): quadros, pinturas e desenhos, feitos inteiramente à mão, e colagens e quadros decorativos semelhantes; gravuras, estampas e litografias, originais; obras originais da arte estatuária e de escultura.

A despeito de a ordem capitalista fazer da arte mercadoria, não se deve concluir que o trabalho artístico abandona suas particularidades ao se tornar um produto comerciável. Ferreira Gullar, na série de artigos reunidos no livro intitulado Argumentação Contra a Morte da Arte (1995), discorre sobre a influência do mercado no processo de criação artística. Apesar de sua posição crítica quanto ao tema, o autor não deixa de reconhecer que a arte, ainda que adquira a qualidade de mercadoria, deve conservar seu caráter de atividade destinada à exteriorização do íntimo do artista:

\footnotetext{
Deve-se entender que, na sociedade da mercadoria, a arte também se transforma em mercadoria. Mas essa não é sua essência. Não se pode levar a tese da arte como produção a ponto de perder-se de vista que ela é, antes que qualquer coisa, uma necessidade humana fundamental (GULLAR, 1995, p. 111).
}

A obra de arte, portanto, ao se inserir em um contexto mercadológico, passa a sustentar a qualidade de mercadoria, o que, contudo, não implica a perda de seu caráter fortemente subjetivo. 
Ainda que se torne produto, permanece fruto da expressão do íntimo de quem a produz. Desse modo, apesar de não escapar à comercialização, a arte conserva peculiaridades que diferenciam seu mercado dos demais setores econômicos. Nesse sentido, afirma Ferreira Gullar:

[...] é diferente a relação do público com a obra de arte e com o objeto industrial. Quem compra um quadro compra-o como objeto de contemplação e de valor cultural. Mesmo quando a razão principal da compra é investir, essa razão se apóia na possibilidade de fruição estética do quadro, na sua condição de obra de arte, e não de objeto utilitário (GULLAR, 1995, p. 17).

A partir da noção de que o trabalho artístico é único, entende-se inexistir a possibilidade de plena substituição de um objeto de arte por outro. Consequentemente, não há produtos similares a determinado quadro ou escultura, por exemplo, como ocorre com as demais espécies de mercadoria. Tal peculiaridade decorre do fato de que o valor da arte está na experiência, ao passo que os outros produtos têm sua importância determinada pelo uso. Por essa razão, conclui-se que a arte, quando transformada em objeto de mercado, possui natureza sui generis, haja vista obedecer a uma lógica diversa das demais mercadorias, pautada primordialmente na singularidade do objeto, que advém da liberdade de criação do artista, a qual, em princípio, não se perde em virtude das leis do mercado, mas, ao contrário, tende a ser mais acentuada na sociedade contemporânea. Segundo Alysson Leandro Mascaro:

A sociedade capitalista altera profundamente a relação entre o produtor e o objeto de arte. A subjetivação do artista é seu elemento central de constituição. Nas relações sociais capitalistas, os vínculos se estabelecem na base da troca de mercadorias. Assim, as formas tradicionais de constrangimento vão paulatinamente diminuindo em favor da afirmação jurídica da liberdade do artista. Não se há de pensar, na dinâmica do capitalismo, na figura do escravo artista, tampouco do servo constrangido à produção da arte. $\mathrm{O}$ artista se individualiza juridicamente, respaldado em direitos subjetivos, e a sua produção entra em circulação com os demais da sociedade por meio de artifícios estipulados de modo contratual (MASCARO, 2015, p. 19).

O artista, sendo livre para criar, produz uma obra marcada pelo seu íntimo, o que engloba não apenas a representação de experiências estritamente pessoais, mas também a exteriorização de sua percepção sobre questões externas, geralmente de cunho social. A subjetividade de seu trabalho persiste ainda que conviva, em maior ou menor grau, com a preocupação comercial. Decerto, a necessidade de transformar sua obra em produto atraente para o mercado influencia o artista, mas não afasta a arte de sua essência eminentemente subjetivista.

Sedimentado o entendimento de que a obra de arte é única e, portanto, insubstituível, verifica-se que a entrada definitiva dessa mercadoria no Brasil deve ser fomentada, com o objetivo de promover o enriquecimento do patrimônio (no sentido amplo do termo) artístico nacional, ainda que a aquisição seja feita por particulares. Por conseguinte, entende-se ser necessário o 
estabelecimento de benefícios fiscais voltados ao ingresso das mercadorias enumeradas no Capítulo 97 da NCM, em especial aquelas referentes a objetos artísticos.

Em virtude da extrafiscalidade dos tributos aduaneiros, a concessão de isenção do imposto sobre a importação se apresenta como medida inicial interessante para a desoneração do ingresso de obras de arte no País.

\section{DA CONCESSÃO DE ISENÇÃO DO IMPOSTO SOBRE A IMPORTAÇÃO A OBRAS DE ARTE ADQUIRIDAS POR PARTICULARES}

O Decreto-Lei n 37/1966, em seu Capítulo III, disciplina a concessão de isenções e reduções do imposto sobre a importação. O artigo 17, caput, estabelece que “A isenção do imposto de importação somente beneficia produto sem similar nacional, em condições de substituir o importado”. O parágrafo único deste artigo, por sua vez, traz as exceções à regra em relação a determinados produtos, como aqueles destinados a fins culturais cujo beneficiário seja entidade sem fins lucrativos (inciso V), do que se infere que pode ser concedida aos produtos excetuados ainda que exista similar nacional. Há pelo menos duas questões a serem enfrentadas a respeito desse dispositivo.

Inicialmente, nota-se a falha do legislador ao mencionar o termo "fins culturais", de modo amplo, na seção que trata da similaridade entre produtos estrangeiros e nacionais como sendo exceção à regra geral de isenção. Isso porque tal expressão engloba diversos artigos insuscetíveis de substituição, devido ao seu valor e natureza artísticos, conforme já explanado. De acordo com Ferreira Gullar, “Ao contrário da produção industrial, que visa à fabricação massiva de objetos iguais, a arte visa à produção de objetos únicos, diferenciados” (GULLAR, 1995, p. 110). A norma prescrita no caput do artigo 17, dessa forma, necessariamente alcança os objetos de arte, o que denuncia não apenas a prescindibilidade, mas também a incoerência do tratamento excepcional dispensado aos bens culturais de modo geral no parágrafo único.

O segundo ponto a ser questionado diz respeito à restrição da possibilidade de se conceder isenção do imposto sobre a importação apenas às doações a entidades sem fins lucrativos. A Lei $n^{\circ}$ 8.961/1994, mencionada neste estudo no item 1, concede isenção a obras de arte de forma ainda mais restritiva, devendo o objeto importado ser destinado a doação a museu instituído e mantido pelo poder público ou por outras entidades culturais reconhecidas como de utilidade pública. Essa limitação é inadequada, pois negligencia as peculiaridades do mercado cultural, o qual não comporta a noção de similaridade entre mercadorias, quando estas são objetos artísticos únicos e originais.

Segundo Regina Helena Costa: 
[...] se há produto similar nacional, a importação do produto estrangeiro será gravada pelo Imposto de Importação, exatamente porque, como visto, a função precípua desse imposto é a proteção da indústria nacional. Diversamente, em se tratando de produto sem similar nacional, em condições de substituir o importado, é caso de isenção, porquanto não há o que proteger (COSTA, 2017, p. 360, grifo nosso).

Constata-se que a ausência de similaridade entre o produto estrangeiro e mercadoria nacional deve ensejar a concessão de isenção àquele em relação ao imposto sobre a importação, uma vez que não há produto brasileiro a ser protegido por intermédio da política tributária. Enquadram-se nesta hipótese as obras de arte, pelas razões já expostas no item anterior.

O imposto sobre a importação, conforme salientado, possui função extrafiscal que se sobrepõe ao objetivo fiscal. Os recursos financeiros por meio dele arrecadados são menos uma finalidade da atividade estatal do que uma mera consequência desta. O tributo em estudo é eminentemente um mecanismo direcionado à promoção do equilíbrio entre os mercados interno e externo. A existência de similar nacional, ou seja, de produto de origem brasileira apto a substituir a mercadoria advinda do exterior, enseja a fixação de alíquota mais elevada, com o intuito de se proteger a produção do Brasil. Entretanto, verifica-se o contrário quando não há produto nacional ou sua oferta é insuficiente, circunstâncias em que o imposto sobre a importação tem alíquotas menos expressivas ou são concedidos benefícios fiscais, haja vista existir então a necessidade de fomento à entrada de mercadorias estrangeiras para suprir a carência em determinado setor do mercado.

Em relação aos objetos de arte, não se pode falar em inexistência ou insuficiência da produção nacional como justificativa para o estímulo à sua importação, uma vez que, desse modo, estar-se-ia introduzindo no mercado artístico a noção de similaridade. Ademais, o Brasil de fato produz arte. Deve-se repisar a conclusão de que uma obra artística não pode ser substituída por ser única, concentrando o seu valor (cultural e de mercado) justamente na sua singularidade.

Dessa forma, ao argumento de que o objeto de arte é insubstituível, une-se a importância desse bem para o incremento do patrimônio cultural do Brasil, o que não ocorre apenas com sua doação a museus. De fato, este parece ser o meio mais democrático de se consumir arte, não podendo, contudo, invalidar a relevância da aquisição de obras por particulares, incluindo-se, aqui, colecionadores e galerias - agentes que possuem grande potencial para o fomento do mercado artístico brasileiro. Ressalte-se que a própria legislação pátria reconhece a importância dos objetos de arte de propriedade privada, nas disposições do Decreto $n^{\circ} 8.124 / 2013$, que regulamenta a Lei $n^{\circ}$ 11.904/2009. Isso porque o referido decreto estabelece a possibilidade de obras de arte pertencentes a coleções particulares serem declaradas como de interesse público, o que legitimaria seu monitoramento pelo Estado. O controle estatal sobre um bem de propriedade particular indica que 
este possui significância para a coletividade, o que, no caso do objeto artístico, relaciona-se com seu valor cultural.

Em estudo inicial sobre a realidade de outros países, é possível identificar os Estados Unidos como os maiores importadores e exportadores de arte, tendo sido responsáveis, em 2010, por 37,6\% das importações e 37\% das exportações no mercado mundial de arte (MACEDO, 2015). Não se podem olvidar as diversas variáveis que influem nestes resultados, mas, ainda assim, é interessante destacar que a legislação norte-americana isenta as obras de arte originais dos tributos aduaneiros, sendo consideradas duty-free (ESTADOS UNIDOS, 2017a, 2017b).

O Reino Unido, que ocupa o segundo lugar no ranking de importações e exportações (MACEDO, 2015), igualmente isenta a importação de obras de arte e de antiguidades de customs duty (tributo aduaneiro), reduzindo, ainda, em 5\% o valor do VAT (Value-Added Tax) ${ }^{5}$ incidente sobre a operação (REINO UNIDO, 2017).

Dentre os vizinhos brasileiros, a Argentina possui legislação tributária propensa ao estímulo a importações de obras de arte. A Lei n 24.633/1996 estabelece isenção nas importações definitivas e temporárias quanto a quaisquer taxas e sobretaxas alfandegárias ou portuárias. Concede, ainda, por meio do Decreto $n^{\circ}$ 279/1997, isenção parcial de 50\% do imposto sobre o valor agregado, fazendo constar neste dispositivo normativo a seguinte justificativa:

Que corresponde fomentar la formación, difusión y desarrollo de la producción artística de nuestro país, dinamizando el mercado interno e incrementando el patrimonio artístico, haciendo mas equitativo el tratamiento tributario a dar a las obras de arte, equiparándolo al otorgado a las distintas expresiones artísticas y culturales (ARGENTINA, 1997) ${ }^{6}$.

A motivação da norma argentina ilustra a importância da promoção de condições propícias ao intercâmbio cultural entre as nações. Há o reconhecimento do impacto da atividade fiscal sobre o mercado de arte e da necessidade de desoneração deste. Este e os demais exemplos ora expostos devem orientar o legislador pátrio a desenvolver mecanismos normativos aptos a fomentarem o ingresso definitivo de obras de arte no País.

Não obstante o imposto sobre a importação, isoladamente, não onerar de modo excessivo o ingresso definitivo de objetos de arte no território nacional, uma vez que sua alíquota tem se mantido em 4\% para os produtos discriminados no Capítulo 97 da NCM, a ausência de isenção relativa a este imposto se apresenta como a primeira questão a ser repensada, em virtude da acentuada função

\footnotetext{
${ }^{5}$ O VAT equivale, nos países de língua portuguesa que adotam um tributo único sobre o consumo, ao imposto sobre o valor agregado ou acrescentado (IVA).

6 “Que corresponde a promover a formação, difusão e desenvolvimento da produção artística do nosso país, revigorando o mercado interno e ampliando o patrimônio artístico, tornando mais equitativo o tratamento tributário a ser dado às obras de arte, equiparando-o com o concedido às diferentes expressões artísticas e culturais” (tradução nossa).
} 
extrafiscal dos tributos aduaneiros. Além disso, integram a base de cálculo do ICMS vinculado à importação os valores dos demais tributos incidentes sobre a entrada de determinada mercadoria no território nacional, do que é possível inferir que a isenção do imposto sobre a importação ensejaria uma redução do imposto estadual, o qual, conforme a Tabela 1, descrita no item 2 deste artigo, é o maior responsável pela alta carga tributária que recai sobre o ingresso definitivo de objetos de arte no País.

A Tabela 2, abaixo, ilustra o potencial impacto da concessão de isenção do imposto sobre a importação a obras de arte e antiguidades, utilizando-se o mesmo exemplo fornecido na Tabela 1, consideradas as alíquotas vigentes em dezembro de 2017, segundo dados da Receita Federal do Brasil e da Secretaria da Fazenda do Estado de São Paulo:

Tabela 2 - Valor da carga tributária incidente sobre a importação de um quadro com valor aduaneiro equivalente a R\$23.000,00 em maio de 2018, considerada a isenção do II

\begin{tabular}{ccc}
\hline Tributo & Alíquota (\%) & Valor (R\$) \\
\hline II & Isenção & Isenção \\
IPI & 0 & 0,00 \\
PIS & 2,10 & 483,00 \\
COFINS & 9,65 & $2.219,50$ \\
Taxa de utilização do Siscomex & & 40,00 \\
ICMS vinculado à importação & 18 & $5.650,79$ \\
$\Sigma$ & & $\mathbf{8 . 3 9 3 , 2 9}$ \\
\hline
\end{tabular}

Fonte: dados obtidos da Receita Federal do Brasil (2018) e da Secretaria da Fazenda do Estado de São Paulo (2018).

Na hipótese ilustrada nas Tabelas 1 e 2, percebe-se que o valor total referente aos tributos devidos passaria de $\mathrm{R} \$$ 9.515,24 (nove mil, quinhentos e quinze reais e vinte e quatro centavos) para R\$ 8.393,29 (oito mil, trezentos e noventa e três reais e vinte e nove centavos), o que representaria uma redução de aproximadamente $11,8 \%$ na carga tributária incidente sobre a importação. O percentual em relação ao valor aduaneiro da mercadoria - $\mathrm{R} \$ 23.000,00$ (vinte e três mil reais) passaria de $41 \%$ para cerca de $36,5 \%$.

Portanto, a concessão de isenção do imposto sobre a importação às mercadorias dispostas no Capítulo 97 (posições 97.01, 97.02 e 97.03) da NCM é de fato apta a ensejar uma consequência prática desejável, não sendo mero preciosismo, para que seja sanada a contradição existente na cobrança do referido imposto sobre mercadorias que não possuem similar no mercado nacional. Ressalte-se que a 
isenção deve ser concedida de modo gratuito, ou seja, sem que se exija do importador qualquer contrapartida. Isso porque, conforme explicitado anteriormente, o ingresso definitivo de objetos de arte no território brasileiro é, por si só, benéfico ao País, seja em termos de fomento à cultura, seja em relação ao aquecimento do mercado artístico nacional.

\section{CONSIDERAÇÕES FINAIS}

O presente estudo evidenciou que a carga tributária incidente sobre a importação de produtos de natureza artística, definidos no Capítulo 97 da NCM, entre as posições 97.01 e 97.03, é significativamente elevada, havendo a necessidade de se estabelecerem benefícios fiscais direcionados ao ingresso em definitivo de obras de arte no território nacional.

A partir da finalidade extrafiscal do imposto sobre a importação, demonstrou-se a incongruência caracterizada pela cobrança de tal tributo sobre o ingresso de objetos de arte no território nacional, em virtude de dois elementos. O primeiro consiste no fato de a obra artística, como mercadoria, ser insuscetível de substituição, não havendo que se aplicar a lógica da similaridade entre produtos. O segundo elemento corresponde ao valor cultural do objeto de arte. A incorporação de obras ao patrimônio de particulares, ainda que não destinadas a museus instituídos e mantidos por instituições sem fins lucrativos, promove o enriquecimento do setor artístico no País, o que, de certo modo, é reconhecido pela própria legislação pátria, ao estabelecer a possibilidade de monitoramento de bens artísticos privados pelo Estado quando declarados de interesse público.

Verificou-se que a concessão de isenção do imposto em questão ensejaria uma redução significativa do montante devido pelo importador em decorrência da atividade tributária, produzindo, desse modo, um efeito prático desejável, apto a estimular o ingresso de bens de valor cultural no Brasil. Contudo, tal medida deve ser entendida apenas como o primeiro passo para o fomento do setor artístico nacional, subsistindo a necessidade de adoção de outros instrumentos direcionados à desoneração da importação de obras de arte, como, por exemplo, o estabelecimento de benefícios fiscais relacionados ao ICMS vinculado à importação e a otimização dos trâmites burocráticos.

\section{REFERÊNCIAS}

ALEXANDRE, Ricardo. Direito tributário. 11. ed. Salvador: Editora JusPodivm, 2017.

AMARO, Luciano. Direito Tributário Brasileiro. 21. ed. São Paulo: Saraiva, 2016. 
ARGENTINA. Decreto $\mathrm{n}^{\circ}$ 279, de 26 de março de 1997. Impuesto al valor agregado (IVA). Venta e importación de obras de arte. Establecese uma alícuota equivalente al cincuenta por ciento de la establecida em el em primer parrafo del artículo 24 de la Ley de IVA. Definición de obra de arte. Condición: Convenio de exhibición. Boletín Oficial de la República Argentina, Poder Ejecutivo Nacional, Buenos Aires, 9 abr. 1997, n. 28.622, p. 3. Disponível em: <https://goo.gl/nwvc3D>. Acesso em: 10 ago. 2018.

ARGENTINA. Lei $\mathrm{n}^{\circ}$ 24.633, de 20 de março de 1996. Disposiciones que se aplicaran a la importación y exportación de obras de arte. Deroguese el Decreto n 159/73 y toda otra disposición que se oponga a la presente. Boletín Oficial de la República Argentina, Congreso de la Nación Argentina, Buenos Aires, 17 abr. 1996. n. 28376, p. 1. Disponível em: <https://goo.gl/FwriRi>. Acesso em: 10 ago. 2018.

ATALIBA, Geraldo. Sistema constitucional tributário brasileiro. São Paulo: RT, 1968.

BARROS, Luiz Celso de. Ciência das Finanças: Direito Financeiro. 4. ed. São Paulo: EDIPRO, 1991.

BRASIL. Constituição da República Federativa do Brasil (1988). Promulgada em 05 de outubro de 1988. Disponível em: <https://goo.gl/HwJ1Q>. Acesso em 23 jul. 2018.

BRASIL. Convênio ICMS 1, de 6 de fevereiro de 2013. Autoriza a concessão de isenção do ICMS em operações com obras de arte na Feira Internacional de Arte do Rio de Janeiro (ArtRio) e na Feira Internacional de Arte de São Paulo (SP Arte). Diário Oficial da União, Conselho Nacional de Política Fazendária (CONFAZ), Brasília, DF, 8 fev. 2013, Seção 1, p. 45. Disponível em: $<$ https://goo.gl/u4DBgd>. Acesso em: 13 dez. 2017.

BRASIL. Decreto $n^{\circ}$ 8.124, de 17 de outubro de 2013. Regulamenta dispositivos da Lei $n^{0} 11.904$, de 14 de janeiro de 2009, que institui o Estatuto de Museus, e da Lei n ${ }^{\circ} 11.906$, de 20 de janeiro de 2009, que cria o Instituto Brasileiro de Museus - IBRAM. Diário Oficial da União, Poder Executivo, Brasília, DF, 18 out. 2013. Seção 1, p. 1. Disponível em: <https://goo.gl/oPJCxW>. Acesso em 22 dez. 2017.

BRASIL. Decreto-Lei no 37, de 18 de novembro de 1966. Dispõe sobre o imposto de importação, reorganiza os serviços aduaneiros e dá outras providências. Diário Oficial da União, Poder Executivo, Brasília, DF, 21 nov. 1966. Seção 1, p. 13.403 (Publicação Original). Diário Oficial da União, Poder Executivo, Brasília, DF, 1 dez. 1966. Seção 1, p. 13.950 (Retificação). Disponível em: $<$ https://goo.gl/TiHxlQ>. Acesso em: 10 jul. 2017.

BRASIL. Instrução Normativa da Receita Federal do Brasil nº 1.788, de 8 de fevereiro de 2018. Aprova o texto consolidado das Notas Explicativas do Sistema Harmonizado de Designação e de Codificação de Mercadorias decorrentes de atualizações publicadas pela Organização Mundial das Alfândegas (OMA). Diário Oficial da União, Secretaria da Receita Federal do Brasil, Brasília, DF, 14 fev. 2018. Seção 1, p. 14. Disponível em: <https://goo.gl/rNoC2N>. Acesso em: 25 mar. 2018.

BRASIL. Lei ${ }^{0}$ 5.172, de 25 de outubro de 1966. Dispõe sobre o Sistema Tributário Nacional e institui normas de direito tributário aplicáveis à União, Estados e Municípios. Denominado Código Tributário Nacional pelo art. $7^{\circ}$ do Ato Complementar $n^{\circ}$ 36, de 13 de março de 1967. Diário Oficial 
da União, Poder Legislativo, Brasília, DF, Seção 1, p. 12.451. Disponível em: $<$ https://goo.gl/RD7EGa>. Acesso em: 10 jul. 2017.

BRASIL. Lei n 8.961, de 23 de dezembro de 1994. Dispõe sobre a isenção do imposto de importação na hipótese que menciona. Diário Oficial da União, Poder Legislativo, Brasília, DF, 24 dez. 1994. Edição extra. Disponível em: <https://goo.gl/AD5z43>. Acesso em: 13 jul. 2017.

BRASIL. Ministério da Indústria, Comércio Exterior e Serviços. Nomenclatura Comum do Mercosul - NCM. Ministério da Indústria, Comércio Exterior e Serviços. Disponível em: <https://goo.gl/cwEaXo>. Acesso em: 20 dez. 2017.

BRASIL. Receita Federal do Brasil. Simulador do Tratamento Tributário e Administrativo das Importações. Secretaria da Receita Federal do Brasil - Ministério da Fazenda. Disponível em: $<$ https://goo.gl/RWTwMM>. Acesso em 19 maio 2018.

BRASIL. Receita Federal do Brasil. Valor aduaneiro da mercadoria. Secretaria da Receita Federal - Ministério da Fazenda. Disponível em: <https://goo.gl/87iNtT>. Acesso em: 16 jul. 2017.

BRASIL. Supremo Tribunal Federal. Agravo Regimental no Recurso Extraordinário $\mathbf{n}^{\circ}$ 1.095.001-SC. Agravante: União. Agravada: SKY Trade Importação e Exportação LTDA. Relator: Ministro Dias Toffoli. Brasília, 6 mar 2018. Disponível em: <https:/goo.gl/odHgMs>. Acesso em: 11 jul. 2018.

BRASIL. Tarifa Externa Comum - TEC. Portal Único Siscomex. Disponível em: <https://goo.gl/V4vh1U>. Acesso em: 16 jul. 2017.

CARVALHO, Paulo de Barros. Curso de Direito Tributário. 21. ed. São Paulo: Saraiva, 2009.

CASTRO, Augusto Olympio Viveiros de. Tratado dos impostos. Rio de Janeiro: Laemmert \& Comp. Editores, 1901.

COSTA, Regina Helena. Curso de direito tributário: Constituição e Código Tributário Nacional. São Paulo: Saraiva, 2017.

ESTADOS UNIDOS. U.S. Department of Homeland Security. Duty on personal and commercial imports of antiques, artwork. U.S. Customs and Border Protection. 2017a. Disponível em: <https://goo.gl/axxuMX>. Acesso em: 19 jul. 2017.

ESTADOS UNIDOS. U.S. Department of Homeland Security. Importing personal and commercial original works of art, paintings, drawings, pastels, collages, decorative plaques, lithographs, original prints and sculptures. U.S. Customs and Border Protection. 2017b. Disponível em: <https://goo.gl/RZmjTW>. Acesso em: 19 jul. 2017.

FIALHO, Ana Letícia (Coord.). Pesquisa setorial: O mercado de arte contemporânea no Brasil. 4. ed. São Paulo: Latitude/ABACT, 2015.

GULLAR, Ferreira. Argumentação contra a morte da arte. 5. ed. Rio de Janeiro: Revan, 1995.

LINTON, Ralph. O Homem: Uma Introdução à Antropologia. São Paulo: Martins Fontes, 1968. 
MACEDO, Leonardo Correia Lima. Objetos de arte no comércio internacional. In: MAMEDE, Gladson; FRANCA FILHO, Marcílio Toscano; RODRIGUES JUNIOR, Otavio Luiz (Org.). Direito da Arte. São Paulo: Atlas, 2015, p. 241-267.

MASCARO, Alysson Leandro. Sobre direito e arte. In: MAMEDE, Gladson; FRANCA FILHO, Marcílio Toscano; RODRIGUES JUNIOR, Otavio Luiz (Org.). Direito da Arte. São Paulo: Atlas, 2015, p. 17-25.

MCANDREW, Clare (Org.) TEFAF Art Market Report 2013: The Global Art Market, with a Focus on China and Brazil. Helvoirt: The Europian Fine Art Foundation (TEFAF), 2013.

REINO UNIDO. Commodity information for 9701100000. Trade Tariff - GOV.UK. 2017. Disponível em: <https://goo.gl/AMiKYP>. Acesso em: 20 jul. 2017.

SÃO PAULO (Estado). Secretaria da Fazenda. Sobre o Comex - Comércio Exterior no âmbito estadual. Secretaria da Fazenda do Estado de São Paulo. Disponível em: <https://goo.gl/9pB6Q9>. Acesso em: 20 maio 2018.

SCHOUERI, Luís Eduardo. Normas tributárias indutoras e intervenção econômica. Rio de Janeiro: Forense, 2005.

TORRES, Ricardo Lobo. Curso de Direito Financeiro e Tributário. 18. ed. Rio de Janeiro: Renovar, 2011.

Elizabete Rosa de Mello Professora Adjunta na Universidade Federal de Juiz de Fora. Doutora em Direito pela Universidade Gama Filho, Mestre em Direito Público pela Universidade Estácio de Sá, Especialista em Direito Público e Direito Privado pela mesma Universidade e Escola da Magistratura do Estado do Rio de Janeiro (EMERJ), Graduada em Direito pela Universidade Estadual Paulista (UNESP).E-mail: elizabeterosademello@gmail.com

Graduanda em Direito pela Universidade Federal de Juiz de Fora E-mail: marialcmorais@outlook.com 